\title{
The future of barriers and trapping methods in the sea lamprey (Petromyzon marinus) control program in the Laurentian Great Lakes
}

\author{
Scott Miehls $\mathbb{D} \cdot$ Paul Sullivan $\cdot$ Michael Twohey $\cdot$ Jessica Barber $\cdot$ \\ Rodney McDonald
}

Received: 29 October 2018/Accepted: 11 November 2019/Published online: 25 November 2019

(C) The Author(s) 2019

\begin{abstract}
A major duty of the Great Lakes Fishery Commission (GLFC), created in 1955, was the development a program of eradication or management of sea lamprey populations in the Great Lakes for the protection of the Great Lakes fishery. Beginning in the 1980s the GLFC shifted sea lamprey control to an integrated pest management model seeking to deploy control measures which target multiple life stages. Currently control efforts focus on limiting the area of infestation using barriers to migratory adults and eradication of larvae from streams using selective
\end{abstract}

Paul Sullivan and Rodney McDonald: retired Fisheries and Oceans Canada.

Michael Twohey: retired U.S. Fish and Wildlife Service.

S. Miehls $(\bowtie)$

U.S. Geological Survey, Great Lakes Science Center,

Hammond Bay Biological Station, 11188 Ray Road,

Millersburg, MI 49759, USA

e-mail: smiehls@usgs.gov

P. Sullivan

Sault Ste. Marie, ON P6A 6J8, Canada

M. Twohey

Marquette, MI 49855, USA

J. Barber

U.S. Fish and Wildlife Service Marquette Biological

Station, 3090 Wright Street, Marquette, MI 49855, USA

R. McDonald

Sault Ste. Marie, ON P6A 2E5, Canada pesticides. Feedback on program effectiveness is obtained by trapping migratory adult lamprey at a series of index sites around the basin. The GLFC continues to support multiple research initiatives to develop additional control, improve current control measures, and further advance the sea lamprey control program. During the past six decades sea lamprey control in the Great Lakes has evolved as the research program has identified technological advances. Here we summarize the current state and recent advancements for two of the sea lamprey control program's core elements, barriers and traps, highlight challenges to be addressed to continue the advancement of these program elements, and provide a series of research questions to spur interest within the research community. Further, because considerable information about these program elements is scattered among grey literature and technical reports, we summarize the history of barriers and traps in sea lamprey control in the included appendices to provide relevant program background to anyone interested in pursuing these research topics.

Keywords Sea lamprey - Laurentian Great Lakes · Migratory barriers · Invasive species · Trapping 


\section{Introduction}

The invasion of sea lamprey into the Laurentian Great Lakes of North America had devastating effects on the Great Lakes ecosystem and regional economy, but also led to the creation of one of the most successful aquatic invasive species control programs globally (Brandt 2019). Though the origin of sea lamprey in Lake Ontario remains uncertain (Eshenroder 2014), the sea lamprey (Petromyzon marinus) was first observed in Lake Erie in 1921 (Dymond 1922). By the late 1930s, sea lamprey had spread to Lakes Huron, Michigan and Superior, where abundances increased rapidly (Smith and Tibbles 1980). Within two decades, uncontrolled sea lamprey predation possibly in addition to unsustainable fishing pressure (Pycha and King 1975; Cobble et al. 1990) had all but eliminated the top predators, lake trout (Salvelinus namaycush) and burbot (Lota lota), from the upper Great Lakes, while decimating stocks of other key commercial, recreational, and Indigenous fishery species, such as lake whitefish (Coregonus clupeaformis) and walleye (Sander vitreus) (Smith and Tibbles 1980). Effects of the sea lamprey rippled through the ecosystem; in the absence of apex predators (lake trout and burbot), populations of other invasive species such as rainbow smelt (Osmerus mordax) and alewife (Alosa pseudoharengus) exploded and massive alewife die-offs fouled beaches and created health hazards in extreme cases (Van Oosten 1947). Commercial fisheries in the Great Lakes collapsed, recreation and the associated businesses disappeared, and the economy of an entire region was crippled. These far-reaching effects provided the impetus for the 1955 Convention on Great Lakes Fisheries between the United States and Canada and the formation of the Great Lakes Fishery Commission (GLFC 1955; http://www.glfc.org/pubs/conv. htm). The GLFC was tasked with creation and implementation of a program to eradicate or minimize sea lamprey populations in the Great Lakes for the protection of the Great Lakes fishery. The GLFC's program of sea lamprey control reduced adult sea lamprey abundance 70-90\% from the pre-control peak (Lawrie 1970; Heinrich et al. 2003). This success is the result of extensive binational collaboration by Sea Lamprey Control Program (SLCP) partners, Fisheries and Oceans Canada and the U.S. Fish and Wildlife Service, with scientific and engineering support from the U.S. Geological Survey and the U.S. Army Corps of Engineers. The SLCP is coordinated through the GLFC and its partners across eight states and the province of Ontario and serves as a model for pest control of an invasive fish species. Beginning in the 1980s the GLFC shifted the sea lamprey control program to an integrated pest management (IPM) model by adopting three critical concepts, (1) control at an optimum benefit to the fish community, (2) use of multiple control methods, and (3) quantitative understanding and system approaches (Sawyer 1980; Christie and Goddard 2003). Currently based on best estimates of economic injury level targets (Irwin et al. 2012), the cost of additional control effort is warranted to sustain a healthy Great Lakes Fishery (Koonce et al. 1993; Larson et al. 2003; Sullivan et al. 2003).

A robust understanding of biology and behavior of the target organism is crucial to the IPM model. Points of vulnerability must be identified throughout the organism's life cycle to facilitate development of multiple control methods which best exploit those vulnerabilities. As such, control of sea lamprey in the Great Lakes started first with an understanding of their complex life cycle (Applegate 1950; Applegate and Smith 1951). In fact, much of what is now known of the sea lamprey life cycle and biology can be directly attributed to their invasion and the demand for control measures in the Laurentian Great Lakes (Hardisty 2006). During the late winter or early spring adult sea lamprey will migrate into tributaries, attracted by river plumes and larval pheromones (Teeter 1980). Larval sea lamprey live burrowed in the stream sediment for 2-7 years. This is a relatively sedentary life stage although recent genetic analysis suggests greater dispersal than previously thought (Sard et al. in press). During mid to late summer, with appropriate cues, presumably both abiotic (temperature) and biotic (size/lipid reserves, thyroid hormones), larvae will metamorphose into their parasitic form (Youson 2003; Manzon et al. 2011) and migrate from the stream to the lakes to seek prey (Youson 1980). In their native range this would be a migration to the ocean, but in the Great Lakes, sea lamprey complete their life cycle entirely in fresh water. Great Lakes sea lamprey will parasitize fish for approximately 12-18 months (depending on spring vs fall outmigration timing) before maturing and seeking a tributary in which to spawn, thus completing their life cycle (Applegate 1950). 
Current sea lamprey control methods focus on the larval and adult life stages, and the two are critically intertwined. Larval sea lamprey are vulnerable to control measures as a result of their relatively sedentary nature in streambeds. Tributaries infested with larval sea lamprey are treated with selective pesticides (hereafter lampricides) that interfere with oxidative ATP production, essentially breaking the energy production cycle at the cellular level (Birceanu et al. 2011; see Wilkie et al. 2019 for synthesis of current lampricide control in the Great Lakes). The area of infestation is confined using barriers to limit the range of adult sea lamprey migrating upstream to spawn. Control of sea lamprey populations in the Great Lakes is currently not possible without lampricides and the current level of suppression is not achievable without barriers concentrating the area of sea lamprey infestation. Barriers not only limit infested stream reaches reducing the cost of treatment, but also improve efficacy of lampricide treatments by preventing access to headwater and dendritic stream regions where lampricide effectiveness can be greatly reduced. This synergy between the two "prongs" of the sea lamprey control program has allowed Great Lakes fisheries managers to undertake native species rehabilitation efforts across the basin. To date, only physical capture and removal (trapping) of migratory stage sea lamprey (juveniles and adults) and the release of sterilized male sea lamprey have been attempted as additional control measures. Though the use of sterilized males has been discontinued (see Bravener and Twohey 2016 for review and analysis of the sterilized male release program), trapping is still used to evaluate SLCP effectiveness (Mullett et al. 2003). The GLFC aims to increase the number of control options in its IPM model (Lamsa et al. 1980; Christie and Goddard 2003), yet decades of research into alternate controls has yielded no additional tools for the SLCP. Here we provide a brief summary of the current state of barriers and traps used by the SLCP and discuss challenges to the continued use and advancement of barriers and traps for sea lamprey control in the Great Lakes.

Current barrier program and the value of barriers for sea lamprey control

Natural barriers (falls, rapids) and numerous preexisting structures, built and owned by private entities and municipal, state, provincial, or federal agencies for purposes other than sea lamprey control (hereafter de facto barriers; Siefkes et al. 2013), represent the preponderance of available protection against upstream migrating adult sea lamprey in numerous and extensive watersheds that would otherwise support sea lamprey reproduction. There are over 5750 tributaries to the Great Lakes totalling more than $595,500 \mathrm{~km}$ of river. Of those tributaries, most of which are surveyed within a 10-year rotation, only 503 have historical records of larval sea lamprey production (Adair and Sullivan 2015). Beginning in 2007, the GLFC implemented the Barrier Inventory and Project Selection System to ground-truth information contained in the U.S. National Inventory of Dams and identify dams among the thousands built for other purposes, such as recreation, flood control, or power generation, that provide effective sea lamprey control. USFWS staff conducted site visits to over 4000 structures, identifying more than 1000 barriers to sea lamprey migration throughout the basin. These de facto barriers provide protection from infestation for more than $300,000 \mathrm{~km}$ of upstream habitat. The online barrier inventory continues to be updated (data.glfc.org). The suite of sea lamprey barriers currently under the GLFC's care and control includes 50 purpose-built structures, as well as 27 de facto barriers, which the GLFC has modified or refurbished to serve a sea lamprey control function (see Zielinski et al. 2019 for a detailed description of current sea lamprey barrier types).

Operation and design improvements have increased the use of seasonally operated barriers which allow sediment transport (outside the sea lamprey migratory period) and passage of stream resident and fall migratory species, however advancement of the sea lamprey control barrier program has been slow. Experimental inflatable-crest barriers were constructed in Big Creek, Ontario and the Big Carp River, Ontario in 1995 featuring crest gates designed by Obermeyer Hydro Incorporated that are raised and lowered through the inflation or deflation of pneumatic bladders. A computerized control system processes data from upstream and downstream water level sensors, controlling the operation of an air compressor to adjust crest height with changing water levels to maintain a constant drop (typically $45 \mathrm{~cm}$; “Appendix 1"). The use of aluminum stoplogs since 1995, as a design component of both new barriers (Venison 
Creek, Ontario, Little Carp River, Ontario, Wesleyville Creek, Ontario, and Orwell Brook, New York) and replacement of fixed-crest barriers (Stokely Creek, Ontario, Gimlet Creek, Ontario and Normandale Creek, Ontario) have made deployment of seasonal structures easier and safer for personnel. Additionally, pre-cast concrete modules can reduce cost and time required for construction of new barriers at suitable locations. For example, Stokely and Gimlet barriers, originally sheetpile construction, were replaced in 2007 and 2008 because of rust-related perforation. Interlocking, concrete modules were precast offsite, transported to the rivers, and assembled in situ, dramatically reducing construction time at the river. These new barriers feature bays into which aluminum stoplogs are placed to block spring sea lamprey migrations and removed during summer to facilitate sediment transport, providing seasonal flexibility and improving connectivity. As part of the focus on alternatives to lampricide control in the early 2000s, the GLFC proposed to construct 100 new purpose-built barriers over a 20-year span and added capacity within the SLCP to accomplish this goal. Despite this impetus and advancements in design, only four new sea lamprey barriers have been built since 2000. Though many alternative barrier designs have been tested, including velocity barriers, electric fields, resistance weirs, flow-through screens, artificiallyenhanced natural drops/slides, bubble screens, acoustic and light deterrents, few have been incorporated into the program (Zielinski et al. 2019).

The value of barriers, purpose-built or de facto, to the SLCP is found in the case of the Manistique River, a large dendritic tributary to Lake Michigan located in Michigan's Upper Peninsula with a drainage area of roughly 500,000 hectares. Deterioration of a mill dam, which previously limited sea lamprey reproduction to the lowest two kilometers of river, continued unabated for decades. By the 1990s, its structural integrity had eroded to the extent that escapement was evident and by the end of the decade, adult sea lamprey had nearly open access to much of the watershed. By 2002, sea lamprey larvae had infested over $440 \mathrm{~km}$ of the watershed, and uncontrolled production of parasitic sea lamprey from a larval population estimated at over $3,000,000$ was reflected in rising estimates of lakewide adult abundance. The first treatment in 2003 required the application of lampricide at 49 locations throughout the watershed and 450 person days to complete, at a cost in excess of $\$ 600,000$. The complexity of the watershed and lack of access for lampricide treatment crews due to remoteness combined to erode treatment efficacy, necessitating subsequent treatments in 2004, 2007, 2009, 2012, 2014, 2016 , and $2019(\$ 960,000)$ to target the large numbers of larvae surviving previous treatments, as well as new recruits.

\section{Current trapping program and limited innovation}

Trapping migratory adult sea lamprey as a control measure has waxed and waned throughout the SLCP's history and though not presently considered a control measure, serves an integral role for assessment. Trapping quickly moved from a control measure to an assessment tool with the advent of lampricides in the 1960s and the once expansive trapping network in the upper Great Lakes quickly shrank (Lawrie 1970). Trapping was revitalized in 1975 when the first portable sea lamprey traps were designed (Schuldt and Heinrich 1982) and installed to fish the face of a St. Marys River power plant, where large numbers of spawning-phase sea lamprey were observed congregating. From the mid-1980s through 2014, a combination of traps (permanent and portable) and nets were operated in about 67 Great Lakes tributaries. Markrecapture estimates, based on a modification of the Schaefer upstream migratory population estimator for Pacific salmon, were systematically employed in most of these streams (Purvis and McDonald 1987). Estimates of lake-wide populations of adult sea lamprey were calculated annually using a combination of mark-recapture estimates for streams with traps and model estimates for streams without traps (Mullett et al. 2003), however this combined approach produced a great deal of uncertainty around the lakewide abundance estimates and has been abandoned. Since 2014, a much-reduced network of proven trapping locations (Fig. 1) has served as an index of adult lamprey abundance and an annual measure of overall program success. Rivers now used as index sites are those with historically low variance $(\mathrm{CV}<20)$ for mark-recapture population estimates. Five to seven index streams in each lake, 29 across the basin are now trapped for assessment (SLCB 2014-01, page 5-21). Beginning in 2018, stream specific sea lamprey abundance is now calculated using the LincolnPetersen estimate of abundance and use of the 


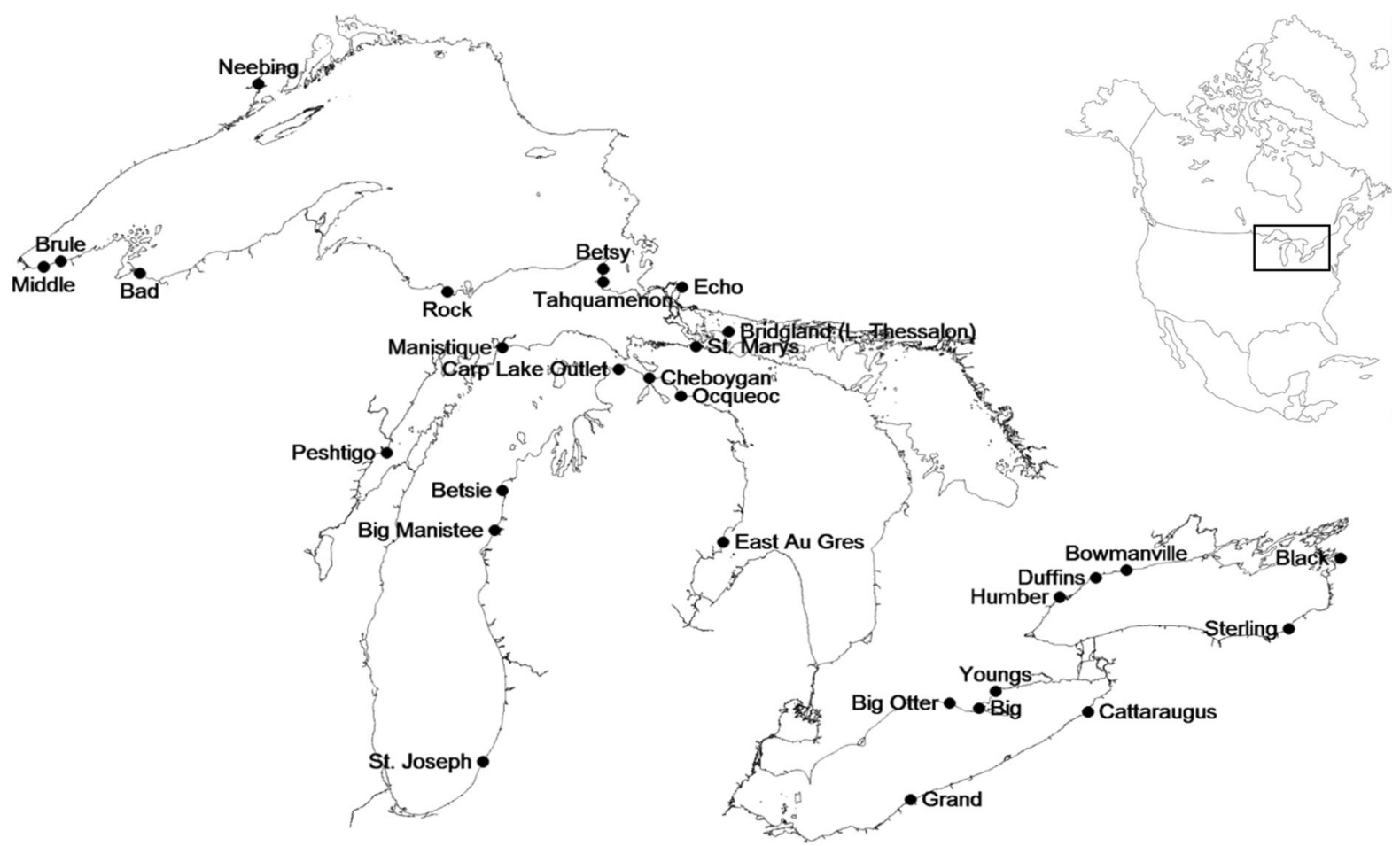

Fig. 1 Locations of Great Lakes tributaries where stream-wide population estimates are used as an index of sea lamprey adult abundance

Schaefer population estimate was discontinued (Barber and Steeves 2019).

As with the sea lamprey barriers little change has occurred in design of the program's assessment traps. Migratory adults are primarily trapped at barriers to upstream migration, typically via passive, barrierintegrated traps. These traps incorporate some form of attractant water flow to exploit the rheotactic response typical of riverine migrants and their strong urge to find passage around obstacles during upstream spawning migrations (Haro and Kynard 1997; Northcote 1984; Kirk et al. 2015). Traps are simple in design; consisting of collection pots fitted with funnels that facilitate entry and discourage escape (Schuldt and Heinrich 1982). Retention devices (one-way fingers) are now often attached to the funnels to allow one-way passage into traps and a few locations incorporate a pre-trap chamber to concentrate and retain sea lamprey near the trap entrance. Recently Department of Fisheries and Oceans has incorporated self-cleaning wedge-wire intake covers (Johnson Screens ${ }^{\circledR}$, Aqseptence Group, Inc.) to upstream intakes to ensure that attractant flows are adequate and consistent (see
"Appendix 2" for detailed description of traps used in the SLCP).

Though the GLFC has dedicated considerable funding support for projects to develop new adult sea lamprey trapping measures, to-date only one new technology has been incorporated into the program. Studded tile panels or eel ladders that allow American eels (Anguilla anguilla) passage around hydropower dams (Solomon and Beach 2004) were first tested as possible sea lamprey trap entrances in 2012 (McDonald and Desrochers 2012). Subsequent testing and development in field settings led to a design that could be incorporated into conventional sea lamprey traps (Reinhardt et al. 2016). This eel ladder style entrance prevented escapement of sea lamprey once inside the trap (100\% retention) and produced capture efficiency results similar to conventional funnel traps. These eel ladder style entrances also eliminate by-catch of nonlamprey species as only those fish using the anguilliform swimming motion (lampreys and eels) can ascend the ramps (Reinhardt and Hrodey 2019). Despite reducing additional labor associated with sorting by-catch for trap crews and reduction in impact 
to native stream fish only one of the 29 index trap sites around the Great Lakes basin has incorporated this technology to date.

The emigration of newly metamorphosed juvenile sea lamprey from streams to the lakes also presents an opportunity for capture and removal. Trapping of this life stage during their downstream migration was conducted during the late 1940s into the 1970s, first as a control measure (Applegate 1950; Applegate and Brynildson 1952) and later to understand sea lamprey life history and ecology (Gabel 1962; Manion and Smith 1978). Early downstream-trapping efforts revealed that juveniles emigrate during a period from October through April, with peak migratory activity occurring during the fall in some streams (e.g. Manion and Smith 1978) and spring in others (Applegate 1961), typically coinciding with periods of increased discharge. Currently rotary screw traps and fyke nets are available within the SLCP for downstream trapping to reduce escapement of juveniles from tributaries in which lampricide treatments are deferred or deemed ineffective. However, efficiency estimates are lacking for these tools and assessment data are insufficient to determine in which tributaries downstream trapping efforts would be most successful. As such, downstream trapping is rarely incorporated into annual sea lamprey control actions.

The only consistent effort to capture downstream migrating juvenile sea lamprey occurs on the St. Marys River, the connecting channel between Lake Superior and Lake Huron, for assessment purposes rather than control. A standardized network of fyke nets has been fished from navigational buoys in the St.

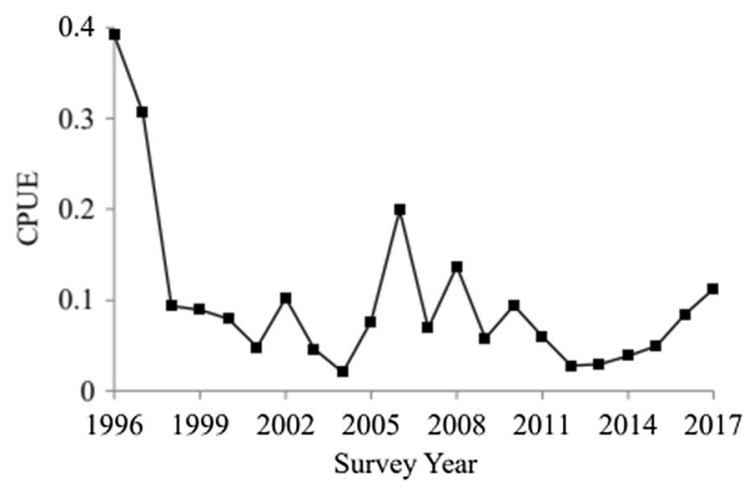

Fig. 2 CPUE (number of out-migrating juvenile Sea Lamprey per net day) of fall fyke netting in the St. Marys River during 1996-2017 (from Sullivan and Mullett 2018)
Marys River annually since 1996 to provide a CPUE index of out-migrating juveniles (Fig. 2; Sullivan and Mullett 2018). Standard $1 \mathrm{~m} \times 2 \mathrm{~m}$ fyke nets are tied to and suspended behind buoys, held at the surface using floats. This method has recently been deployed in the St. Clair River (connecting tributary between lakes Huron and Erie; Sullivan and Adair 2012). Catches likely represent a small fraction of the parasites produced in these large rivers, however, the resulting data yield an index supportive of other assessment measures and the methodology provides a means to verify or monitor recruitment from large tributaries that are difficult to assess by standard gear (Sullivan and Adair 2012).

\section{Challenges and opportunities}

Barriers

Numerous case studies are available to understand the impact barrier removals would have on sea lamprey control in the Great Lakes basin, yet pressure for barrier removal continues to build. The case of the Manistique River provides real world evidence of what the loss of even a single barrier on a large watershed could mean for sea lamprey control. Conservation efforts in the sea lamprey native range provide further evidence of the impact of dam removal on reestablishment of lamprey populations (Hogg et al. 2013; Lasne et al. 2014; Pereira et al. 2017). Further, sea lamprey control personnel now quantify larval habitat, and abundance and distribution of native lamprey above barriers that are breached or considered for removal as a surrogate for sea lamprey production potential above barriers in the Great Lakes (pers. comm. Tanya Van Kempen, Department of Fisheries and Oceans, Canada, Sault Ste Marie, Ontario) such as the case of a barrier on the Black Sturgeon River, Ontario (Smyth 2011). Primary challenges to the use of barriers for sea lamprey control can fall into one of several general categories, deterioration, inundation, fish passage, and human safety, any one of which provide compelling arguments for barrier removal and warrant thorough consideration.

Trade-offs between fish passage gains when barriers are removed compared to increased costs of lamprey control and possible reduced effectiveness 
need to be fully evaluated (Lavis et al. 2003; McLaughlin et al. 2013). Specifically, regarding cost of control, more lampricide and more staff time will be required to treat additional stream reaches when barriers are removed. Increased availability of spawning and larval habitat will likely result in increased larval abundance and even if treatment efficacy remains constant more parasites will be produced increasing damage sustained by the fishery. However, increased stream complexity, which is typical in upstream reaches, can erode treatment efficacy, likely compounding the effect of the barrier removal on parasite production further increasing damage to the fishery. Finally, when lampricides are applied to previously untreated reaches, native lamprey populations in those reaches will be impacted along with sea lamprey larvae. In conducting these cost-benefit analyses, the impact of a barrier removal must consider not just monetary costs but also biological and ecological impacts and at the appropriate spatial scale. Too often impacts of a barrier removal are evaluated only at the stream level (Kemp and O'Hanley 2010), whereas impacts occur across the entire lake (Moody et al. 2017; Jensen and Jones 2018). For example, when the Jensen and Jones (2018) model evaluated the removal of a de facto barrier on the Grand River, Michigan, a feedback was observed where increased production in the Grand River resulted in increased production for sea lamprey in tributaries around Lake Michigan, amplifying the impact of the barrier removal on system-wide sea lamprey abundance. This example demonstrates the necessity to consider negative impacts associated with increased access of invasive species to suitable spawning and nursery habitat at appropriate spatial scales, so these impacts are fully realized during the decisionmaking process (McLaughlin et al. 2013). The complexity and variability of stream morphology, biological, and social issues among streams where barrier removals are considered require that removals (and alternatively barrier construction) be evaluated on a case-by-case basis. Clearly barriers will impact stream flow and the fish community, as will lampricide treatments and the potential for increased production of invasive species. Therefore, cost-benefit decision analyses such as that conducted for removal of a barrier on the Black Sturgeon River, Ontario (Smyth 2011) should continue to be utilized for management decisions, and management evaluation models (Jensen and Jones 2018) can aid these decision processes because of the complexity involved in considering all possible impacts at both the stream and lake wide spatial scales.

The loss of functionality of de facto barriers, through neglect (deterioration), intentional removal, or inundation resulting from changing flow regimes, poses the single greatest challenge to the ongoing delivery of effective sea lamprey control in the Great Lakes (Lavis et al. 2003). Many dams are no longer used for their original purpose, have been abandoned by their original owners, and are deteriorating. Average lifespan of a barrier is expected to be 50 years and many de facto barriers upon which sea lamprey control relies are beyond that potential lifespan. Because refurbishment and maintenance of existing dams is expensive, it is often beyond the means of private landowners, municipalities, or individual state and provincial agencies, resulting in many groups opting for barrier removal. Barrier removal relieves the original owner of the financial and safety liabilities of dam ownership but then deflects the costs for controlling an expanded aquatic invasive species population often to federally-funded agencies. Environmental conditions are also in flux and a changing climate is increasing the frequency and severity of spring floods. If this trend continues low-head structures that block spring sea lamprey migrations will require renovation to prevent inundation. If sea lamprey control is to continue at the current level of suppression, a means to limit the area of sea lamprey infestation is necessary and currently physical migratory barriers are the only tool available to the SLCP to achieve that goal.

Dam removal has become a focus area to support increased connectivity for resident and migrating fish species. Fishery management plans for the Great Lakes specify a commitment "to remove or bypass barriers on Great Lakes tributaries to facilitate fish passage", while at the same time committing to "control established invasive species." (Great Lakes Restoration Initiative Action Plan II). For that reason, selective passage of non-target species (native migratory fishes and introduced salmonids) around sea lamprey barriers has become one of the highest priorities of the GLFC and SLCP (O'Connor et al. 2003; Coscarelli et al. 2011). Indeed, the GLFC has begun a major initiative on the Boardman River, Michigan to test and develop selective fish passage 
tools for Great Lakes migratory species (Zielinski et al. 2019; http://www.glfc.org/fishpass.php). Most purpose-built sea lamprey barriers are low-head design and pool-and-weir passage structures at a few de facto barriers allow passage of salmonids, yet native Great Lakes species do not possess strong jumping abilities and are often blocked by these structures. Trap-and-sort fishways are currently operated at four purpose-built barriers. However, most tributaries where purpose-built barriers have been constructed are small and the width physically precludes construction of trap and sort facilities. The added costs of design, construction, maintenance, and operation, as well as variable effectiveness (Pratt et al. 2006, 2009), has limited broader application of this approach to streams with de facto barriers. Many of the challenges encountered in the Great Lakes are the same wherever fish passage structures are constructed and include, entrance design and placement, attraction of fish to the entrance, motivation of fish to ascend the passage structure, and delays in migration timing. Further, limited understanding of the species to be passed and the number of those fish needed for meaningful population-level impact on recruitment hinders advancement of fish passage research and design.

Finally, Human safety around barriers remains a concern. A condition known as a "submerged hydraulic jump" can develop immediately downstream of low-head dams that poses a threat to human safety (Leutheusser and Birk 1991; Mazurek et al. 2008). Water plunging over the crest creates a vortex in the vertical plane between the surface and stream bed, causing objects in the water to be entrained and trapped against the downstream side of the weir (Lopez-Egea 2015). The water in this zone is highly aerated, greatly reducing its density and hence, its buoyancy. The combination of turbulent conditions and low buoyancy can be deadly, as anyone falling into the water below the dam may be trapped in the vortex and drown (Hotchkiss 2001). Research to mitigate the creation of a submerged hydraulic jump has focused on spillway designs that dissipate the energy of water falling over the crest (Mazurek et al. 2008; Lopez-Egea 2015), however, this approach may compromise sea lamprey control function by reducing the height of vertical drop. Jumping pools of strategically-placed concrete blocks and specifically-designed concrete aprons have been installed at some sites to disrupt the vortex and mitigate the problem. Anecdotal observation suggests that some sloped-crest barriers such as the barrier on the Grand River, Lake Michigan can be successful at blocking sea lamprey though swimming performance studies indicate passage should be possible. Better understanding is required of how velocity, substrate, slope, and other potential factors, such as migratory drive of the animals themselves, interplay to influence sea lamprey swimming performance and ability to pass blocking structures.

Seasonal barriers provide an attractive alternative to permanent structures by allowing seasonal connectivity, but the use of seasonal structures has been limited despite demonstrated successes within the program. Clearly fixed barriers will block all nonjumping fish species, but limited understanding of sea lamprey migration timing and what contribution early and late-run lamprey might make to eventual recruitment in the system remain the primary challenge (McLaughlin et al. 2007). Recently, sea lamprey have been documented entering streams as early as March (McCann et al. 2018), captured at sites $37 \mathrm{~km}$ upstream of the river mouth in a large river system by late April (Miehls and Siefkes 2015), and captured entering streams as late as August (pers. comm. Nick Johnson, U.S. Geological Survey, Millersburg, MI). Historically, lamprey have been observed in streams nearly every month of the year (Applegate 1950; Purvis and McDonald 1987). To block $99 \%$ of the upstream sea lamprey migration using seasonally deployed barriers, $44-100 \%$ of the migrations of non-target species will also be blocked (Velez-Espino et al. 2011). Despite the challenges, seasonal barriers can be effective and continue to be used for sea lamprey control. For example, since 1990 GLFC has constructed or modified 26 barriers for sea lamprey control; 13 of these barriers are maintained by DFO and 13 are maintained by USFWS. Of these new barriers, 18 have the capacity to be and 13 currently are operated seasonally. Timing of seasonal barrier operation in Canada is determined by DFO SLCP personnel whereas, operation schedules in the United States are determined by fishery management agencies. Regardless, those barriers operated seasonally have successfully eliminated or reduced reproduction upstream, except for the inflatable crest barrier installed on Big Creek, Lake Erie which has suffered multiple mechanical failures since installation. 
However, extensive refurbishments in 2019, including replacement of the computerized operating system, air compressor, supply lines, and level sensors, are expected to increase reliability of this structure in the future. Sightings of sea lampreys outside the operating period (March through mid-July on the lower lakes), are rare, little evidence of successful reproduction has been found, and lampricide treatments have not been warranted above the SLCP seasonally operated structures. For example, a seasonal barrier on Orwell Brook, New York is opened in mid-July each year as mandated by the New York Department of Environment and Conservation and no sea lamprey larvae have been detected upstream since construction in 2013. Seasonal operation allows unimpeded passage of fall migratory spawning fish species and sediment transport; and outside the period of operation allows movement of river-resident species and eliminates safety concerns related to the dangerous hydraulic created downstream of low-head barriers under high flow conditions.

\section{Adult sea lamprey trapping}

The GLFC has invested considerable research efforts into improving the existing network of adult sea lamprey traps, specifically to increase rates of encounter, entrance, and retention (Bravener and McLaughlin 2013). Trap entrance design is not standardized across the program and improved designs may bolster entrance rates (Hrodey et al. 2017). For example, McLean et al. (2015) observed that as few as $20 \%$ of lamprey approaching a trap entrance entered the trap. Further, low encounter rates at some trapping locations may play a considerably larger role in overall trap effectiveness. For example, spatial mismatch was observed between acoustically-tagged sea lamprey in the St. Marys River and the trap placement at a large barrier (power generation facility) with lamprey most often resting at the base of the dam but spending little time near the surface-fishing traps. During the spring migratory season, sea lamprey spent, on average, $55 \mathrm{~h}$ at the barrier but were available to the overhead traps between 2 and 500 s per individual (Rous et al. 2017). Improving encounter rates may result from a better understanding of how sea lamprey navigate river channels and complex flows to optimize trap design and placement. Extensive work has been conducted describing habitat preference, upstream movement, and migration routes across numerous tributaries to the Great Lakes (USFWS Annual Reports 1981, 1982; Kelso and Gardner 2000; Kelso et al. 2001; SLCC Annual Reports 1998, 2003; Holbrook et al. 2015, 2016), yet little description is available for fine-scale navigation and response to complex flows often encountered at trapping and fish passage structures. Rates of entrance and retention can be highly variable among trapping sites due to environmental conditions (Dawson et al. 2015; Bravener and McLaughlin 2013). For example, sea lamprey demonstrate a positive rheotactic response to flow and by increasing flow near traps the number of lamprey approaching and subsequently entering the traps could be increased (Bravener and McLaughlin 2013). However, the number of sea lamprey escaping those traps also increases with increased flow, resulting in no net change to the number captured and removed from the system (Rous et al. 2017). Substantial room for improvement remains in all aspects of capturing and removing sea lamprey from a stream and the GLFC has continued an aggressive research program in chemosensory communication (Green et al. 2017) to improve encounter rates both through attraction to traps using mating or migratory pheromones ( $\mathrm{Li}$ et al. 2007) as well as repulsion using an alarm cue (Imre et al. 2010; Bals and Wagner 2012) or predator cue (Imre et al. 2014) or a combination of the two (Hume et al. 2015). In addition, recent work with portable electric guidance tools has demonstrated capture success with greater than $70 \%$ removal rate, (Johnson et al. 2017) and may hold promise for trapping at locations away from physical barriers.

Despite the bulk of GLFC funded research focusing on improving trap effectiveness, the greatest hurdle for advancing trapping (or any measure targeting adult lamprey lifestage) from an assessment tool to a control method is the limited understanding of sea lamprey biology. This uncertainty stems from the lack of a clear stock recruitment relationship (Dawson and Jones 2009), the potential for compensatory mechanisms by affected larval populations (Jones et al. 2003), and the ability of sea lamprey to successfully reproduce even at extremely low abundance when Allee affects might be observed for other species. Deployment of lampricide to reduce larval populations in nursery streams provides a relatively clear metric for success; less clear is the metric of reproductive suppression achieved by control measures 
implemented at the adult life stage. Control measures enacted when adult sea lamprey are migrating upstream to spawn are far removed, in terms of life stage, from the metric used to evaluate that tool, the lake wide parasitic abundance estimate. Sea lamprey are prolific spawners; mating pairs can locate one another at low population densities, largely because of chemosensory-driven migratory behavior (Johnson et al. 2009). Further, females are highly fecund, meaning small numbers of adults can quickly repopulate a system with larvae (Pereira et al. 2017). Regardless, managers must make decisions about the SLCP direction in the face of this uncertainty.

Research questions should address which control strategies targeting migratory sea lamprey will most influence recruitment of parasites returning to the lake. Here, the critical question to address is: Can additional sea lamprey control be achieved by further limiting access to tributaries (barriers) or by removing prespawn adults (trapping)? Questions remain as to how we might improve capture and removal rates; however, research seeking to advance adult control measures needs to first identify how and when adult sea lamprey control tools could be implemented within an already effective program and how impact of additional control measures will be evaluated.

\section{Migratory juvenile sea lamprey trapping}

The downstream migratory life stage of newly metamorphosed juvenile sea lamprey presents a potentially vulnerable point during the life cycle closest to the ultimate control program goal-reduction of damage to the fishery. Yet of the three life stages likely vulnerable to control, this remains least studied and understanding of juvenile lamprey behavior is limited. Early control program efforts tell us that downstream migration may be protracted, lasting from October through April (Applegate 1950). However, a large proportion of the population may be vulnerable to capture during a limited number of days (Sotola et al. 2018) resulting from flood pulses triggering lamprey to move en masse, and migration appears to be limited largely to hours of darkness at least during the fall and winter (Miehls et al. 2019). Though downstream movement appears to occur largely during flood pulses, the exact mechanisms triggering the initiation of migration are unknown. So is the reason why the timing of migration can vary so greatly among individuals over the 6-month migratory period, even within a single stream. Juvenile lamprey present in large connecting channels such as the St Marys River are not exposed to flood pulses on a scale experienced by lamprey in smaller streams; water velocity, depth and likely even turbidity remain relatively constant in these large systems yet juvenile sea lamprey still undergo downstream migration.

Beyond understanding timing, development of truly effective means to capture and remove juvenile sea lamprey will require an understanding of how they migrate. Downstream migratory juvenile sea lamprey appear to be more prevalent in higher flow regions of the stream (Sotola et al. 2018) and may even select for higher water velocity areas (Bracken and Lucas 2013) where use of conventional gear is not feasible. To that end, non-physical stimuli such as electric fields (Johnson et al. 2014) low frequency sound (Mickle et al. 2018), light, and alarm cues (Johnson et al. in press) have been or are currently being tested as possible guidance tools to redirect juvenile lamprey into stream regions where conventional trapping gear can operate effectively. Typically migrating during flood pulses yet possessing relatively poor swimming ability makes development of guidance tools for this life stage challenging (Miehls et al. 2017a, b). Juvenile lamprey simply lack the swimming performance necessary to avoid many guidance devices (Moser et al. 2015). Development of guidance and trapping technologies will need to take into consideration behavior, such as propensity to move in the higher flow regions of the stream, whether downstream movement is active (swimming head-first, holding station) or passive (drifting with current) as well as limited swimming ability to respond to stimuli.

\section{Summary}

Crucial to the IPM model is a robust understanding of biology and behavior of the target organism. Identifying points of vulnerability throughout the organism's life cycle will facilitate development of multiple control methods. Uncertainty and implementation challenges at each of these points serve to guide future research. As novel management tools are proposed, developed and tested researchers must keep in mind the challenges presented by sea lamprey biology and clearly define how new control measures 
might benefit sea lamprey control in the Great Lakes. Clear rationale for where the use of alternate or supplemental experimental control measures might fit into the sea lamprey IPM model should be part of any experimental control research moving forward. Below we pose a series of questions (by no means exhaustive) identifying information gaps critical to advancing the barrier and trapping programs for sea lamprey control in the Great Lakes.

\section{Migratory barriers}

- How can the SLCP prioritize maintenance or reconstruction of dams that serve a sea lamprey control function? This is the most important challenge faced by the SLCP, as the removal or failure of a sea lamprey barrier represents replacement of the most effective control method with a less effective one. The Manistique River provides an example of the costs associated when a single important barrier is breached. How many structures can be rendered ineffective for blocking sea lamprey before a tipping point is reached, and control becomes untenable?

- In the case of the Manistique barrier the breach resulted from deterioration, however increased flooding resulting from climate change threatens the effectiveness old and new structures alike. Many low-head structures throughout the basin are potentially at risk of inundation as flow regimes change, but without accurate predictive flow models the control program cannot prioritize resources for improving or reinforcing these structures.

- What variables drive recruitment and how do they influence survival and lampricide effectiveness across different stream conditions? Simulation models are available to evaluate tradeoffs for barrier removal (Jensen and Jones 2018) and other SLCP management actions (Jones et al. 2009); however, these simulations are only as good as the data used to build them, hence improved understanding of the biological parameters that drive stock-recruitment is needed. For example, mortality (natural and lampricide induced) is currently generalized across the Great Lakes basin (Jones et al. 2009), yet we know these values can vary considerably for individual streams (Dawson and Jones 2009).

- Beyond trap and sort operations, what tools are available to separate sea lamprey from other migratory or resident stream fishes to facilitate passage of desirable species around sea lamprey barriers? This is especially challenging for typical, (non-jumping) native Great Lakes fishes.

- How do velocity, substrate, slope, and other potential factors, including motivation of the lamprey themselves, interplay to influence sea lamprey swimming performance and how can these be exploited for next generation sea lamprey barriers?

- What contribution to overall recruitment do early, middle, and late run sea lamprey provide? i.e. Do seasonal barriers need to block $100 \%$ of the sea lamprey spawning migration to still be effective control tools?

Adult sea lamprey trapping

- What does the removal of an adult sea lamprey mean for production of parasites from a given stream? We know that mating success, larval survival, and lampricide effectiveness vary among streams so understanding the environmental factors that influence those rates would guide deployment of not only adult sea lamprey trapping but all control measures targeting the adult sea lamprey life stage. Further, how will climate change affect these variables and what will those effects mean for adult sea lamprey control measures.

- Encounter rate is likely the single biggest factor influencing sea lamprey trap success (Bravener and McLaughlin 2013), so how can trap encounter rates be improved; both the proportion of the lamprey population that encounters a trap and the duration of encounter? How do sea lamprey navigate stream channels during spawning migrations? What stream characteristics and/or flow dynamics influence migration routes and behavior?

- Conventional trap entrances (funnels) are not attractive to sea lamprey, so do better options exist for removal of sea lamprey from the spawning population within a given stream? Alternatively, can migratory adult sea lamprey be entrained into 
unsuitable regions of a tributary (ecological traps) such that physical removal would not be necessary.

- What percent of migrants survive to spawning? What factors contribute to survival? i.e. When during the migratory season is the removal of adults most effective for reducing reproductive potential?

Juvenile sea lamprey trapping

- What abiotic or biotic cues trigger downstream migration? Can the timing of downstream migration be predicted more accurately to reduce the duration that juvenile lamprey control measures must be deployed? Can downstream migratory activity be induced?

- How do juvenile sea lamprey undergo downstream migration? Where in the stream channel do they migrate? Is downstream migration an active or passive event?

- What is the survival rate during downstream migration? Does that rate vary across stream types or reaches and what factors contribute to that variability (i.e. are some streams more important for control than others) and can those factors be manipulated (i.e. increased predation)?

- How do juvenile sea lamprey find prey after reaching the lotic environment? Can their prey finding behavior be used for control?

Sea lamprey control and research in the Great Lakes offer a unique opportunity for researchers and SLCP agents to work side by side. A wealth of historical data provide a solid foundation for researchers to develop strong hypotheses and the opportunity to work directly with managers can lead to research questions with immediate impacts. Research to understand sea lamprey biology for development of control tools has led to advances in fields such as neuroscience, biomedicine and evolutionary ecology. Much of the knowledge gained about sea lamprey biology, behavior, and physiology has resulted directly from attempts to control them in the Great Lakes. As sea lamprey research continues, efforts should be made to ensure dissemination of results not only to Great Lakes SLCP managers but also fishery managers coordinating the conservation of this species in its native range where it is widely imperiled. Likewise, research and conservation efforts on sea lamprey in their native range should be considered and utilized whenever possible for continued development of control measures.

Open Access This article is distributed under the terms of the Creative Commons Attribution 4.0 International License (http:// creativecommons.org/licenses/by/4.0/), which permits unrestricted use, distribution, and reproduction in any medium, provided you give appropriate credit to the original author(s) and the source, provide a link to the Creative Commons license, and indicate if changes were made.

\section{Appendix 1: Use of migratory barriers for sea lamprey control}

\section{Barrier program history}

Sea lamprey control in the Laurentian Great Lakes can trace its roots to the construction of a mechanical weir on the Ocqueoc River, Michigan Lake Huron, in 1944 (Shetter 1945, 1949). This was followed soon after by construction of weirs on Little Thessalon River, (also Bridgeland Creek, Lake Huron) in 1946 (MacKay and MacGillivray 1949); Carp Creek (renamed Black Mallard River, Lake Huron) in 1947; and a more permanent structure on the Ocqueoc River in 1948 (Applegate 1950). With development of selective lampricides still years away, and a desperate need to curb the damage that sea lamprey were inflicting on valuable fish stocks, management agencies constructed 20 mechanical barriers in tributaries to the Upper Great Lakes from 1950 to 1951 (Applegate and Smith 1951). Several designs were tried and most barriers or weirs incorporated a trap to remove sea lamprey prior to spawning (Applegate 1950). These early control efforts included large, permanent weirs and traps, portable weirs and traps for small to medium streams, permanent dams, and even dams with inclined-screen traps (Applegate et al. 1952) to target downstream migrating juvenile sea lamprey. Initially, sea lamprey were collected at most barrier sites and absolute catch numbers were used as an index of abundance. One early experimental structure on the Black River, Michigan (Lake Michigan) combined a low-head design and an overhanging steel lip (Stauffer 1964) which prevented sea lamprey from jumping over low-head structures. This overhanging steel lip proved to be an important advancement in design and 
remains a feature of most purpose-built barriers currently in operation.

Mechanical weirs were effective, but were also expensive to construct and operate, and subject to inundation during high water events, making them vulnerable to escapement when floods coincided with spawning migrations. To address these inherent weaknesses, researchers began field experiments with electricity in 1951, installing an electric fish screen and weir on the Chocolay River, Michigan Lake Superior, and an electromechanical barrier (an electrode array coupled with a mechanical trap) on the Ocqueoc River (Applegate et al. 1952). This was followed by the construction of various electric field barriers in several streams during 1952 (Applegate et al. 1952). These early studies led to implementation of an operational control program on Lake Superior (selected as being the last Great Lake to harbor significant Lake Trout populations), with the construction between 1953 and 1954 of 43 electromechanical barriers along its southern shore. From 1954 to 1958, the Fisheries Research Board of Canada (FRB) installed electro-mechanical barriers in 38 east and north shore Lake Superior tributaries, as well as two physical dams. By 1960, 162 electromechanical barriers (97 in Lake Superior, 65 in Lake Michigan) had been constructed (Smith and Tibbles 1980). Commencing in 1965, a network of electric field barriers was installed in streams of the Ontario waters of northern and eastern Lake Huron, peaking at ten sites on nine streams for the 1967 migratory season. These Ontario weirs, in conjunction with the U.S. Ocqueoc River device, provided an abundance index from 1967 to 1975 (Smith and Tibbles 1980, updated by Purvis and McDonald 1987).

A variety of designs and electrode configurations were employed across the Canadian and U.S. weirs (Lenson and Lawrie 1959; McLain et al. 1965), however the expense of construction, operation, and maintenance, escapement resulting from "holes" in electric fields around traps or flood damage, and the high mortality rates on non-target species inflicted by the use of 60-cycle, 110- or 220-volt, alternating current (Erkkila et al. 1956; Scott 1959) illustrated technological limitations. Deterrents to reduce nontarget injuries were tested, such as upstream and downstream mechanical fences (Lenson and Lawrie 1959) and direct current (DC) diverting or blocking devices (Scott 1959; McLain et al. 1965, FRB annual reports of 1958 and 1959). However, the discovery of selective lampricides during this same time brought about the realization that effective control could be achieved by targeting larvae in nursery streams. Consequently, most of the structures that comprised the expansive electrical barrier network on lakes Superior and Michigan were decommissioned following the 1967 season (Smith and Tibbles 1980), leaving only a select array to assist with the evaluation of the evolving lampricide treatment program, with the last of these removed after the 1979 migratory run. The Lake Huron network soon followed, with the last electric weirs (the Koshkawong and Ocqueoc rivers) removed in 1980 (Purvis and McDonald 1987).

Detailed weir operational information for this early period and catch data by lake, stream, and year are available in annual reports of the Institute for Fisheries Research of the Michigan Department of Conservation (1944-1950), of the International Sea Lamprey Committee (1946-1951) and its successors-the Sea Lamprey and Lake Trout Committee (1952) and The Great Lakes Fishery Committee (1953-1957), of the Canadian Federal-Provincial Great Lakes Fisheries Research Committee (1953-1956), of the Hammond Bay Biological Station of USFWS (1950-1956), of the FRB (1956-1966) and, as the GLFC assumed its operational role commencing July 1 1956, of the annual reports of the Marquette and Ludington stations of the USFWS (MBS, LBS) from 1956 on, and of the Sea Lamprey Control Centre (SLCC) beginning 1966.

Several barrier designs are currently used in the SLCP with a simple low-head design being the most widely used of the purpose-built barriers. This design has several advantages, including lower construction costs, minimal impoundment of upstream water, and minor impairment of sediment transport and upstream passage of jumping fish. Purpose-built sea lamprey barriers are designed to promote containment of the water course within its banks in most years, reducing the probability of upstream flooding. Sea lamprey can jump only short heights (Applegate 1950; Reinhardt et al. 2009), do so erratically and seldom on a trajectory that would help them to surmount an obstacle (Youngs 1979). Thus, a relatively short vertical drop is enough to prevent their upstream passage. Based on the results of trials in the Cayuga Lake Inlet during 1978-1979 that involved approximately 3000 sea lamprey, researchers concluded that a 
$30 \mathrm{~cm}$ vertical drop was effective in blocking $100 \%$ of the migrants (Hunn and Youngs 1980), a finding confirmed more recently by Reinhardt et al. (2009). A combination of research and in situ observations of sea lamprey at barriers has led to the formulation and adoption of the following guidelines for crest height by the GLFC and its agents: an operational head of $75 \mathrm{~cm}$ during summer (normal flow); $45 \mathrm{~cm}$-head during spring runoff; $15-\mathrm{cm}$ head under conditions of mean annual flood; and installation of a sheet steel lip with an overhang of $15-30 \mathrm{~cm}$ to further ensure against escapement.

\section{Barrier types used for sea lamprey control}

\section{Fixed-crest barriers}

One of the earliest methods employed to control sea lamprey was the construction of fixed-crest barriers in nursery streams to prevent adults from accessing suitable spawning habitat. Once the electrical barrier network was decommissioned in the 1960s and 1970s, mechanical barriers featuring a fixed-crest design were constructed in increasing numbers (39 purposebuilt barriers and 25 GLFC-modified dams, as of this document being published). In its simplest form, a fixed-crest barrier can be achieved by modifying bedrock in a stream bed to create a vertical drop sufficient to block sea lamprey, as was done in the French (Smith and Tibbles 1980) and Manitou rivers and Prince Creek; however, most are constructed of steel sheet pile or concrete, and may include an integrated sea lamprey trap or trap-and-sort fishway. They do however require a substantial head during normal to low water conditions in order to meet the height criteria during high water or acceptable flooding events.

Migrating Pacific lamprey (Entosphenus tridentatus) can ascend steeply inclined and even vertical faces to a surprising degree using an "attach-twitch-attach" behaviour (Reinhardt et al. 2008), however, Reinhardt et al. (2009) reported that neither this behaviour, nor the ability to scale a barrier by jumping, has been observed in sea lamprey. Another ability of Pacific lamprey to stack en masse into a corner of or a slot in a dam to negate a vertical drop may be possible to a lesser degree by Great Lakes sea lamprey, as reported by Applegate (1950), and as witnessed at the Little Rapids falls on Little Thessalon River and at the
Duffins Creek barrier, Ontario Lake Ontario, both singular events (pers. comm., Rodney McDonald, Fisheries and Oceans Canada, Sault St. Marie, Ont.).

\section{Adjustable-crest barriers}

The GLFC has constructed 14 adjustable-crest barriers, including those with removable stop logs (11) or mechanical gates (1) that can be manipulated manually, or inflatable crests that use computerized control systems to automatically adjust crest height (2). Examples of manually operated barriers include Orwell Brook, New York (Lake Ontario; stop logs), and Albany Creek, New York (Lake Ontario; lift gate), although the latter is currently operated as a stationary fixed-crest barrier. In the last decade, several adjustable-crest barriers have replaced deteriorating fixedcrest barriers in Ontario tributaries to provide the option for seasonal operation, the ability to fine-tune crest height, or the flexibility to retrofit fish passage devices post-construction: Gimlet Creek (Lake Superior), Stokely Creek (Lake Superior), Normandale Creek (Lake Erie), and Still River (Lake Huron). Of these, only the Normandale Creek barrier is operated seasonally, however, the others have the capacity for seasonal operation should a future need arise.

As substantial temporal overlap exists in the spawning phenology of sea lamprey and other nonjumping fish, seasonal operation provides minimal benefit for passing species that migrate in spring, and hence, the operational period should be timed to maximize sea lamprey suppression, rather than to accommodate the migrations of other species (Klingler et al. 2003). However, benefits include the seasonal elimination of dangerous hydraulic conditions associated with low-head dams and the facilitation of sediment transport, movement of stream residents, and passage of fall migrants. These benefits are achieved at the risk of escapement if the operational period fails to encompass the entire sea lamprey migration, which is subject to annual and geographic variation in factors that influence the timing of the run (Binder et al. 2010). In some cases, seasonal operation may be required by permitting agencies, and the SLCP are currently developing protocols to guide the operation of seasonal barriers, based on program experience, and region- or stream-specific data on the timing of sea lamprey migrations, water temperature, and discharge. 
Experimental inflatable-crest barriers were constructed in Big Creek and the Big Carp River in 1995. Each features crest gates designed by Obermeyer Hydro Incorporated that are raised and lowered through the inflation or deflation of pneumatic bladders. A computerized control system processes data from upstream and downstream water level sensors, controlling the operation of an air compressor to adjust crest height with changing water levels to maintain a constant drop (typically $45 \mathrm{~cm}$ ). The Big Creek and Big Carp River barriers are operated, with some variation, between mid-March and late July, and are lowered to the stream bed during other periods to permit unimpeded passage of resident aquatic organisms and recreational paddlers. Unfortunately, air leaks, torn air bladder, control system faults, level sensor and power failures have interrupted the function of these structures since their construction, to the extent that escapement has necessitated the continuation of periodic lampricide treatment above the Big Creek barrier. Extensive refurbishments in 2019, including replacement of the computerized operating system, air compressor, supply lines, and level sensors, are expected to increase reliability of this structure in the future. Larval assessments in the Big Carp River indicate that the barrier has been effective in eliminating the need for periodic treatments. The Big Carp barrier is located near the Sea Lamprey Control Centre, allowing faults to be quickly remedied. Also, the numbers of sea lamprey that challenge the Big Carp barrier are quite low (3-41 trapped annually, 2010-2014) when compared with Big Creek (1772-3366 trapped annually since 2010), significantly reducing the risk of escapement.

\section{Hybrid barriers}

The hybridization of different designs led to the development of three experimental barriers. The first, a velocity barrier constructed in the McIntyre River, Ontario, combined a fixed-crest with a velocity chute incorporating a mesh lining to which sea lamprey could not attach. The second is a flow-through barrier on the Little Thessalon River, Ontario, which incorporates removable flow through screens. The third, on the Ocqueoc River, Michigan, is an electromechanical barrier that combines a fixed-crest barrier with a DC electric field (above the barrier) that activates only when the fixed barrier is inundated to a depth that lamprey can swim over.

The use of water velocity to block the upstream passage of sea lamprey is intriguing because of the potential to pass non-jumping fish without requiring laborious manual sorting. Research generally suggests that the anguilliform swimming mode of lampreys is slower and less powerful than the subcarangiform mode demonstrated by most migrating teleost fishes in the Great Lakes, and that the sea lamprey's inferior endurance can be exploited by eliminating its ability to attach to the substrate and rest (McAuley 1996). However, the ability of lampreys to attach to smooth surfaces would appear to offer an advantage for moving upstream against a current, and sea lamprey are known to employ an "attach-burst-attach" motion to facilitate horizontal countercurrent movement (Hanson 1980; Reinhardt et al. 2009). Challenges to designing a successful velocity barrier include the positive correlation of sea lamprey swimming speed and endurance with body size and water temperature (Beamish 1974). Sea lamprey can attain burst speeds exceeding $4 \mathrm{~m} \mathrm{~s}^{-1}$ over a $1-3 \mathrm{~s}$ period and move upstream against velocities of up to $3.9 \mathrm{~m} \mathrm{~s}^{-1}$ without attaching to the substrate (Hanson 1980), leading some to conclude that the use of velocity barriers for control purposes would be impractical (Hanson 1980; Hunn and Youngs 1980). However, these studies were limited in sample size and methodology, and sea lamprey swimming ability continues to be evaluated.

The only field test of a velocity barrier occurred on the McIntyre River, as noted above (McAuley 1996). The structure combined a fixed crest weir fabricated of steel sheet pile with a velocity chute consisting of a rectangular wooden flume that was $8.5 \mathrm{~m}$ long and $2.4 \mathrm{~m}$ wide, with a $2 \%$ grade over its length, and lined with plastic mesh to prevent attachment. Results from the first two years of operation were promising (Young et al. 1996), based on the suppression of nest counts to near zero in 1994 (despite a major inundation of the barrier) and to zero in 1995 and the considerable reduction in appropriate-age larvae from surveys conducted upstream of the barrier (those found being largely attributed to escapement past the barrier during the 1994 flood). Further, the passage of fish species under consideration appeared uninterrupted, supporting a principal goal of the design concept. However, assessments from 1996 to 2005 revealed annual recruitment of sea lamprey larvae in upstream areas, 
thus confirming that escapement was occurring with regularity. The causes for this escapement are unknown, but potentially include: inundations of the barrier during subsequent flood events; inadequate water velocity due to low discharge or debris in the chute; deterioration of the attachment-resistant lining of the chute over time, facilitating attachment and upstream movement; and holes or openings in the barrier's crib-work face of sufficient size to allow passage. Given that evaluation of this pilot barrier was flawed, the concept may remain viable and worthy of further study. Further, Youngs (1979), as a by-product of his investigations into vertical-drop thresholds for barrier designs, found lamprey were confused by current patterns formed below a Cipolletti weir and suggested that "It would be worthwhile to run further experiments with similar structures perhaps in conjunction with a velocity barrier."

An experimental flow-through barrier with fixed trap, based on the original mechanical and electrical weirs used in the program, and improved on by SLCC to help address the pressing need of the Sterile Male Program for more males, was designed for and installed in a North Channel, Lake Huron stream (Little Thessalon River) in the fall of 1998, at the site of a traditional portable trapping operation at Little Rapids, replacing it. A concrete apron was laid down across the stream, anchored into each bank by concrete abutments, with a series of H-style beams embedded vertically, at regular intervals through the concrete into the substrate. The vertical columns allow insertion and removal of aluminum screen panels. A large screen-walled trap permanently mounted to the apron adjacent to the one accessible shoreline completed the array. The apron was stepped down several centimeters around the trap to concentrate flows near and through the trap at low water. The screens were seasonally placed to form a blocking and guiding barrier, with the feature of having the water flow through (run of the river) rather than building upstream and flowing over the structure. The new device was a success, with a post 4-year (1999-2002) mean in trapping effectiveness of $73 \%$ versus a 4 -year average for the previous portable operation (1995-1998) of 26\%. It remains operating despite some issues having required redress (chiefly undermining of apron, occasional accumulation of debris and a few non-target mortalities). Such a barrier, within limits, may have appeal at sites where a full barrier faces resistance.

The Ocqueoc River barrier features a low-head fixed crest dam that blocks sea lamprey migrations at low to moderate stream discharge but, during high water events an electrical field is automatically activated between the two abutments and vertically from the crest to the surface of the overlying water. The electric field is generated from four horizontal electrodes made of railroad rail embedded into a concrete sill on the upstream side of the barrier crest. Line power is converted to pulsed DC by Smith-Root pulsators (Smith-Root, Inc., Vancouver, WA) with waveform and pulse characteristics controlled by Smith-Root Fish Barrier Software. The Ocqueoc River barrier is the only remaining electric barrier in the Great Lakes. The design with the fixed-crest low-head barrier that blocks non-jumping fishes during normal flow conditions and the electric field that activates only during floods appears to function well as an upstream deterrent for migrating adult sea lamprey. Occasional sea lamprey recruitment upstream of the barrier has been observed but has been attributed to ongoing sea lamprey research in the upper watershed.

\section{Appendix 2: Traps used by the great lakes sea lamprey control program}

\section{Trapping program history}

Sea lamprey control in the Great Lakes began with trapping and though not effective for population suppression, trapping has been part of the SLCP for nearly eight decades. The first sea lamprey traps in the Great Lakes were mechanical weirs targeting the adult life stage and offered little success as control measures. They eventually were operated to mitigate nontarget injury at electric barriers and served as a tool to assess the distributional limits of lake populations. Their use lapsed as the chemical control program grew. Trapping was revitalized in 1975 when the first portable sea lamprey traps were designed (Schuldt and Heinrich 1982) and installed to fish the face of a St. Marys River power plant, below which United States Army Corps of Engineers personnel had witnessed large numbers of spawning-phase sea lamprey congregating. The demonstrated success and efficiency of portable traps in the St. Marys River and later at other 
migratory barriers, combined with hoop nets and mechanical weirs displaced electric weirs as the control program's primary assessment tool. Removable mechanical trapping networks expanded across all lakes through the 1980s and early 1990s. Beyond the essential assessment role, this trapping network became integral to research and development of alternative control methods and provided the source of specimens used in sterilized male release operations (Bravener and Twohey 2016). Permanent traps were routinely incorporated into the design of the new barriers, beginning with the 1969 construction of Denny's Dam, Saugeen River, Ontario, Lake Huron and were retrofitted to existing purpose-built sea lamprey barriers (example Young's Creek, Ontario, Lake Erie). These permanent structures were less vulnerable to fluctuating stream conditions, offered controllable attractant water flow, and were safer for personnel to operate, all of which resulted in improved trapping effectiveness and greater reliance on permanent structures for assessment and specimen collection.

From the mid-1980s through 2014, a combination of traps (permanent and portable) and nets were operated in about 67 Great Lakes tributaries. Markrecapture estimates, based on a modification of the Schaefer upstream migratory population estimator for West Coast salmon (J. Heinrich, U.S. Fish and Wildlife Service, Marquette, MI), were systematically employed in most of these streams (Purvis and McDonald 1987). Estimates of lake-wide populations of adult sea lamprey were calculated annually from a combination of reliable mark-recapture estimates for streams with traps and model estimates for streams without traps (Mullett et al. 2003). Since 2014, a much-reduced index network of proven trapping operations (29 streams basin wide), with reliable catches and consistently viable estimates, has served as an index of adult lamprey abundance and an annual measure of overall program success (J. Adams, U.S. Geological Survey, pers. comm.).

Trapping of newly-metamorphosed juvenile sea lamprey during their downstream migration was conducted during the late 1940s into the 1970s, first as a control measure (Applegate 1950; Applegate and Brynildson 1952) and later to understand sea lamprey life history and ecology (Gabel 1962; Manion and Smith 1978). Downstream migrants were first collected using inclined screen traps built into barriers that diverted all or most of the stream flow through screening to separate debris and juvenile lamprey from the water. Early downstream-trapping efforts revealed that juveniles emigrate during a period from October through April, with peak migratory activity occurring during the fall in some streams (e.g. Manion and Smith 1978) and spring in others (Applegate 1961), typically coinciding with periods of increased discharge. In the early 1960s the US Coast Guard reported observations of newly metamorphosed, parasitic phase sea lamprey attached to the transoms of their large boats moored in Sault Michigan. This unusual observation spurred researchers to deploy various collection methods, including surface tow nets, dip nets and an electrified otter trawl, at different times of the year and in multiple locations within the river's turning basin. These efforts captured 2012 recently metamorphosed sea lamprey between 1963 and 1966, which were tagged and released to study parasitic sea lamprey movement in lakes Huron and Michigan (Moore et al. 1974). The use of surface tow nets below the Edison Sault power plant in late fall proved most effective and other methods, times, and locations were abandoned (Dahl 1968). Trawling efforts were standardized in 1964 to provide a unique index of relative abundance, although mark-recapture was largely abandoned after 1966. Catch-per-unit-effort (\# per trawl hour) declined steadily until 1981, after which the trawling index in the St. Marys River was discontinued (SLCC annual reports of the period). More recently, downstream trapping with rotary screw traps and fyke nets has been used to reduce escapement of juveniles from tributaries in which lampricide treatments are deferred or deemed ineffective, though capture efficiency is lacking for these downstream capture techniques.

\section{Current sea lamprey trap types}

Technologies used at present to capture adult sea lamprey are passive systems that exploit the strong urge of sea lamprey to find passage around streamborn obstacles during their upstream spawning migration. When an obstacle or barrier to migration is encountered, a sea lamprey will explore its face and contiguous stream banks, aggressively probing for any indication of flow that may guide it past the blockage (a positive rheotactic response). Exploiting this behavior, traps with funnel entrances are placed adjacent to or against a substantial obstacle or 
complete barrier (natural or manmade). Traps are oriented within the existing currents to maximize the available attractant flow of water or mechanically fed same from upstream. Funnels are designed to facilitate entry and discourage escape. Operated in this manner, traps have proven highly effective at capturing sea lamprey. As a further augmentation, retention devices may be attached to the funnels to allow one-way passage into traps. Retention devices are imperfect, allowing some escapement and possibly discouraging some entrances, but tested instances increase trap captures (McDonald and Stamplecoskie 2010; Hrodey et al. 2017).

- Nets fyke, hoop or D-ring nets are used in small wadeable sections of streams where barriers are not available for trapping. These nets have long leads to guide lampreys to the funnel. Nets are labor intensive (require lots of cleaning); are prone to failure from floods, debris, and animals; and typically have low efficiencies $(<30 \%)$.

- Portable assessment traps are rectangular sheet mesh cages hung from a structure in a stream seasonally (Schuldt and Heinrich 1982). Their portability allows fine-scale adjustment in a variety of locations, though operating efficiencies can be highly variable and are often less effective on large rivers.

- Semi-portable structures are structures where the framework such as a concrete sill stay in the river year-round but the weir panels (Little Thessalon River, Ontario, Lake Huron) or the trap structure itself (Manistique River, Michigan, Lake Michigan) or trap inserts (Cheboygan River, Michigan, Lake Huron) can be removed and stored over winter. The two highest efficiency traps in the Great Lakes basin (Cheboygan River, Little Thessalon River) fall in this category.

- Permanent traps are structures that have been permanently engineered into a barrier and provide consistent and optimal operating characteristics at that site. Operating efficiencies are usually high $(>50 \%)$ and less variable than portables. This is attributed to their stability, ability to fish under a wide variety of conditions, increased capacity, and (a feature held to be essential to their operation and success) attractant water flow leaving the entrance, normally delivered to the trap from upstream.
Experimental sea lamprey trapping

- Refuge or shelter traps Sea lamprey are assumed to be photophobic, as they typically migrate at night and typically seek shelter during daylight hours, until the urge to spawn supersedes the need to hide. Early during development of the portal trapping network, solid-sided triangular traps (aluminum or galvanized steel) of various sizes were deployed. Typically, smaller than the standard rectangular trap, these traps were fishable in tighter locations within smaller streams and were intended to take advantage of their darkened interior to retain specimens and were intended to be fished in locations with little natural refuge. While also referred to as refugia or cryptic traps, this category of trapping device has several variants which are typically named for the materials from which they are made, hence pipe (tube) traps or bucket traps. Lamprey are typically captured earlier during the migratory season in these refuge traps but capture rates are low requiring the deployment of many individual traps or gangs of these traps. The laborintensive nature and low efficiency of these traps eventually led to their discontinuation within the control program in favor of the barrier integrated traps. Recent informational needs (better-describing the timing and behavior of the start of the upstream runs, obtaining specimens from that earliest part of the migration for specific types of study, validating the mark-recapture method in use at traps) demanded that sea lamprey researchers turn to a means of capturing specimens well downstream of current trap sites or from streams without conventional traps, and at the earliest possible times and the use of refuge traps was resurrected for the purpose. Interestingly, one study documented that marked lamprey captured early during the migratory season from refuge traps were recaptured at lower rates compared to lamprey used for program mark-recapture assessment or not recaptured at all in conventional traps (Hrodey and Bravener 2011). Recent work on behavior may lend insight to this discrepancy as lamprey appear to exhibit varying degrees of shyness or boldness (McLean and McLaughlin 2018) and poses concerns for an assessment program reliant on a single trap design. 
- Lighted traps With a nearly opposite conceptual model as that for use of refuge traps, lighted traps have been employed and tested to a limited extent. Lighted trap entrances in at least one scenario enhanced catch dramatically (Purvis et al. 1985) and proved effective to increase entrance rates in a laboratory setting (Stamplecoskie et al. 2012). However, results were inconclusive when deployed in the field (Stamplecoskie et al. 2012), and other efforts to use lights for trapping or behavioral manipulation of migratory adults demonstrated little effect (Fredricks et al. 1996; Miehls et al. 2017a, b). Sea lamprey are only active at night during at least the early portion of the migratory season but seem to abandon the photophobic response later during the season when more mature and when water temperatures are greater than 16C (Binder and McDonald 2008). As such, timing and maturation level may explain some of the contradictory results.

- Fish wheels Fish wheels are relied on by commercial salmon fisheries to harvest salmon from river reaches that are hazardous for boating and lack an obstruction (dam, rapids or such) to impede and concentrate the run. Size of the fish stock must be substantial to ensure a meaningful catch in these huge river systems. Attempting to work at choke points along the river risks encountering excessive velocities for the wheel to safely and effectively handle. Since these massive structures are fished below river bottom at the lowest point of the wheel's travel, another prerequisite is a bed of light gravel or sand sufficiently near shore for anchoring and servicing into which the wheel can dig.

In 2005, USFWS brought in a $1.2 \mathrm{~m}$ wheel to fish in the Cheboygan River, Lake Huron. With one of the largest runs of sea lamprey in the Great Lakes, and a suitable location believed to straddle the main path used by the migrating adults, this offered an opportunity to thoroughly test the concept and the appropriateness of the specific size of wheel on-hand. It was concluded after a few years of operation that, while less cost-effective as the traditional barrier integrated traps, the fish wheel warranted continued testing as a possible open river assessment tool. In 2008, a $3 \mathrm{~m}$ wheel was obtained from the USGS, North Carolina Cooperative Fish and Wildlife Research Unit, Raleigh, North Carolina (home of the first wheel in
North America-1829). Miehls and Siefkes (2015) concluded after a 2-year investigation using the $3 \mathrm{~m}$ fishwheel in the Manistee River, Lake Michigan that a stand-alone fish wheel was ineffectual in an open river scenario (away from a barrier) but might function as part of a fish passage structure as it captured considerable numbers of walleye and steelhead with minimal sea lamprey numbers.

- Eel ladders Sloped surfaces, if not overly steep, are regularly challenged by sea lamprey, and a percentage may be successful. Observations at a $5 \mathrm{~m}$ dam on North Creek, tributary to Big Creek, Lake Erie, revealed that during a scrubbing of the angled face to remove algae water was released to create a minor wash down the surface and this was sufficient to trigger lamprey to ascend well up the face by a series of upward bursts with a considerable sideways component. In travelling back and forth while ascending, lamprey reached heights where a breach of the top appeared feasible, although not witnessed (nor was a larval population subsequently found upstream). Similar climbs, only in wet grass, have also been reported from Rydal Bank Dam on the Thessalon River and a site in Thunder Bay. Shorter ascents have been observed by field personnel at Quance Dam on the same Big Creek.

Under laboratory conditions, $91 \%$ of sea lamprey tested, ascended a traditional eel ladder ramp with staggered pegs, and $100 \%$ were retained in the collecting box. Later work tested different slopes, arrangements of the pegs, and quantity of water required, ultimately achieving $96 \%$ ascension rates with or without water and at slopes up to $80^{\circ}$, depending on the pattern of pegs (D'Aguiar 2011). Field comparisons demonstrated similar overall catch rates between eel ladder style traps and conventional funnel traps (Reinhardt et al. 2016). However, capture probability for male and female lamprey differed with trap style (eel ladder vs funnel) and river (Reinhardt and Hrodey 2019). This line of research warrants continued investigation to determine impact on population assessment efforts.

- Juvenile nets Two designs have been used for assessment, experimental collection efforts and limited alternative control-the traditional fyke net and drift nets. These nets require smaller mesh 
relative to the adult nets, typically $3 / 8^{\prime \prime}$ mesh or smaller. Fyke nets have been deployed either anchored in place fishing near the bottom or suspended. Fyke nets anchored to the substrate typically incorporate wings to increase fishing area. Anchored fyke nets are the most common control response to limit outmigrants reaching the lake when a stream is unable to be treated with lampricide and escapement is expected. Fyke nets have also been deployed for assessment in the St. Marys and St. Clair rivers to provide an index of parasites emigrating from those large connecting channels. In these systems fyke nets are equipped with floats and suspended from navigation buoys to fish the upper $1 \mathrm{~m}$ of the water column. The DFO, Sea Lamprey Control Centre has conducted fyke net sampling in the St. Marys River since 1996 and has maintained a consistent outmigrating juvenile index since 1998 (pers. comm. Gale Bravener, Fisheries and Oceans Canada, Sault Ste. Marie, Ontario). St. Clair River sampling began in 2011 (pers. comm., Pete Hrodey, U.S. Fish and Wildlife Service, Marquette, MI). Little information is available about efficiency of fyke nets for juvenile lamprey as effectiveness will likely be determined by the proportion of the stream discharge that is fished (Sotola et al. 2018) assuming the timing of gear deployment is able to match the timing of downstream migration given the challenges of operating conventional nets during fall through spring when migration typically occurs. Hanson and Swink (1989) estimated that fyke nets deployed in the Ocqueoc River, Michigan captured between 1 and $12 \%$ of marked sea lamprey during mark and recapture studies conducted 1963-1968.

- Juvenile rotary screw traps As of this publication the SLCP owns three rotary screw traps which have been deployed for both assessment and as a secondary control measure. These traps consist of a rotary drum, inside a fixed auger which is driven by water flow. Volkhardt et al. (2007) provides thorough description of device operation. Again, effectiveness of these tools has not been evaluated and likely varies with location. A more thorough analysis of cost to operate versus benefit in terms of parasitic lamprey removal is needed.

\section{References}

Adair R, Sullivan P (2015) Sea lamprey control in the Great Lakes 2014. Annual report to the Great Lakes Fishery Commission, GLFC, Ann Arbor, p 111

Applegate VC (1950) Natural history of the sea lamprey (Petromyzon marinus) in Michigan. U.S. Fish and Wildlife Service Special Science Report, Fisheries No. 55, p 247

Applegate VC (1961) Downstream movement of lampreys and fishes in the Carp Lake River, Michigan. U.S. Fish and Wildlife Service Special Science Report, Fisheries No. 387, p 71

Applegate VC, Brynildson CL (1952) Downstream movement of recently transformed sea lamprey, Petromyzon marinus, in the Carp Lake River, Michigan. Trans Am Fish Soc 81:275-290

Applegate VC, Smith BR (1951) Sea lamprey spawning runs in the Great Lakes, 1950. U.S. Fish and Wildlife Service Special Science Report, Fisheries No. 61, p 49

Applegate VC, Smith BR, Nielsen WL (1952) Use of electricity in the control of sea lamprey: electromechanical weirs and traps and electrical barriers. U.S. Fish and Wildlife Service Special Science Report, Fisheries No. 92, p 52

Bals JD, Wagner CM (2012) Behavioural responses of sea lamprey (Petromyzon marinus) to a putative alarm cue derived from conspecific and heterospecific sources. Behaviour 149:901-923

Barber J, Steeves M (2019) Sea lamprey control in the Great Lakes 2018. Annual report to the Great Lakes Fishery Commission, Great Lakes Fishery Commission, Ann Arbor

Beamish FWH (1974) Swimming performance of adult sea lamprey, Petromyzon marinus, in relation to weight and temperature. Trans Am Fish Soc 103:355-358

Binder TR, McDonald DG (2008) The role of temperature in controlling diel activity in upstream migrant sea lampreys (Petromyzon marinus). Can J Fish Aquat Sci 65:1113-1121

Binder TR, McLaughlin RL, McDonald DG (2010) Relative importance of water temperature, water level, and lunar cycle to migratory activity in spawning-phase sea lamprey in Lake Ontario. Trans Am Fish Soc 139:700-712

Birceanu O, McClelland GB, Wang YS, Brown JCL, Wilkie MP (2011) The lampricide 3-trifluoromethyl-4-nitrophenol (TFM) uncouples mitochondrial oxidative phosphorylation in both sea lamprey (Petromyzon marinus) and TFM-tolerant rainbow trout (Oncorhynchus mykiss). Comp Biochem Physiol C: Toxicol Pharmacol 153:342-349

Bracken FSA, Lucas MC (2013) Potential impacts of smallscale hydroelectric power generation on downstream moving lampreys. River Res Appl 29:1073-1081

Brandt C (2019) Great Lakes sea lamprey: the 70 year war on a biological invader. University of Michigan Press, Ann Arbor, p 180

Bravener GB, McLaughlin RL (2013) A behavioural framework for trapping success and its application to invasive sea lamprey. Can J Fish Aquat Sci 70:1438-1446

Bravener G, Twohey M (2016) Evaluation of a sterile-male release technique: a case study of invasive sea lamprey 
control in a tributary of the Laurentian Great Lakes. N Am J Fish Manag 36:1125-1138

Christie GC, Goddard CI (2003) Sea Lamprey International Symposium (SLIS II): advances in the integrated management of sea lampreys in the Great Lakes. J Great Lakes Res 29:1-14

Cobble DW, Bruesewitz RE, Fratt TW, Scheirer JW (1990) Lake trout, sea lampreys, and overfishing in the upper great lakes: a review and reanalysis. Trans Am Fish Soc 119:985-995

Coscarelli MA, Elliot RF, Forsythe PS, Holey ME (2011) Enhancing lake sturgeon passage at hydroelectric facilities in the Great Lakes. Project report Great Lakes Fishery Trust, Lansing, p 22

D'Aguiar M. (2011) The ability of sea lamprey (Petromyzon marinus) to utilize solid structural components to climb inclined surfaces. Dissertation, University of Guelph

Dahl FH (1968) A surface tow net for collection of parasiticphase sea lampreys. Prog Fish Cult 30:183-184

Dawson H, Jones ML (2009) Factors affecting recruitment dynamics of Great Lakes sea lamprey (Petromyzon marinus) populations. J Great Lakes Res 35:353-360

Dawson HA, Quintella BR, Almeida PR, Treble AJ, Jolley JC (2015) The ecology of larval and metamorphosing lampreys. In: Docker MF (ed) Lampreys: biology, conservation, and control. Fish and fisheries, series 37. Springer, Dordrecht

Dymond JR (1922) A provisional list of fishes of Lake Erie. Univ Toronto Stud Biol Ser Publ Ont Fish Res Lab 4:57-73

Erkkila LF, Smith BR, McLain AL (1956) Sea lamprey control on the Great Lakes 1953 and 1954. U.S. Fish and Wildlife Service Special Science Report, Fisheries No. 175, p 27

Eshenroder RL (2014) The role of the Champlain Canal and Erie Canal as Putative Corridors for colonization of Lake Champlain and Lake Ontario by Sea Lampreys. Trans Am Fish Soc 143:634-649

Fredricks KT, Swink WD, Montouri L (1996) Feasiblity of using strobe lights to direct sea lamprey movement. Project completion report, Great Lakes Fishery Commission, Ann Arbor, p 9

Gabel JA (1962) Report on Bad River fyke net operations. Technical report, Bureau of Commercial Fisheries, Biological Station, Marquette, p 23

GLFC (1955) Convention on great lakes fisheries. Great Lakes Fishery Commission, Ann Arbor

Great Lakes Fishery Commission (1990) Minutes of the annual meeting of the great lakes fishery commission, April 1990 App. XVII. Great Lakes Fishery Commission, Ann Arbor, pp 303-113

Green WW, Boyes K, McFadden C, Daghfous G, Auclair F, Zhang H, Li W, Dubuc R, Zielinski BS (2017) Odorant organization in the olfactory bulb of the sea lamprey. J Exp Biol 220:1350-1359

Hanson LH (1980) 1980 Study to determine the burst swimming speed of spawning-run sea lamprey (Petromyzon marinus). U.S. Fish and Wildlife Service Research Completion Report, Millersburg, Michigan, p 16

Hanson LH, Swink WD (1989) Downstream migration of recently metamorphosed sea lampreys in the Ocqueoc River, Michigan, before and after treatment with lampricides. N Am J Fish Manag 9:327-331
Hardisty MW (2006) Lampreys life without jaws. Forrest Text, Cardigan, p 272

Haro A, Kynard B (1997) Video evaluation of passage efficiency of American shad and sea lamprey in a modified Ice Harbor fishway. N Am J Fish Manag 17:981-987

Heinrich JW, Mullett KM, Hansen MJ, Adams JV, Klar GT, Johnson DA, Christie GC, Young RJ (2003) Sea lamprey abundance and management in Lake Superior 1957-1999. J Great Lakes Res 29(Suppl 1):566-583

Hogg R, Coghlan SM Jr, Zydlewski J (2013) Anadromous sea lampreys recolonize a Maine coastal river tributary after dam removal. Trans Am Fish Soc 142:1381-1394

Holbrook CM, Bergstedt R, Adams NS, Hatton TW, McLaughlin RL (2015) Fine-scale pathways used by adult sea lamprey during riverine spawning migrations. Trans Am Fish Soc 144:549-562

Holbrook CM, Bergstedt RA, Barber J, Bravener GA, Jones ML, Krueger CC (2016) Evaluating harvest-based control of invasive fish with telemetry: performance of sea lamprey traps in the Great Lakes. Ecol Appl 26:1595-1609

Hotchkiss RH (2001) Flow over a "killer" weir design project. J Hydraul Eng 127:1022-1027

Hrodey PJ, Bravener G (2011). Evaluation of tube traps to capture migrating, spawning-phase sea lampreys. Technical report to the Sea Lamprey Control Board, Great Lakes Fishery Commission, Ann Arbor, p 7

Hrodey PJ, Bravener G, Miehls SM (2017) Effects of trap funnel and finger design on sea lamprey entrance and retention. Project completion report 2015_HRO_76002, Great Lakes Fishery Commission, Ann Arbor, p 25

Hume B, Meckley TD, Johnson NS, Luhring TM, Siefkes MJ, Wagner CM (2015) Application of a putative alarm cue hastens the arrival of invasive sea lamprey (Petromyzon marinus) at a trapping location. Can J Fish Aquat Sci 72:1799-1806

Hunn JB, Youngs WD (1980) Role of physical barriers in the control of sea lamprey (Petromyzon marinus). Can J Fish Aquat Sci 37:2118-2122

Imre I, Brown GE, Bergstedt RA, McDonald R (2010) Use of chemosensory cues as repellents for sea lamprey: potential directions for population management. J Great Lakes Res 36:790-793

Imre I, Di Ricco RT, Belanger CF, Brown GE, Johnson NS (2014) The behavioural response of adult Petromyzon marinus to damage-released alarm and predator cues. J Fish Biol 84:1490-1502

Irwin BJ, Liu W, Bence JR, Jones ML (2012) Defining economic injury levels for sea lamprey control in the Great Lakes Basin. N Am J Fish Manag 32:760-771

Jensen AJ, Jones ML (2018) Forecasting the response of Great Lakes sea lamprey (Petromyzon marinus) to barrier removals. Can J Fish Aquat Sci 75:1415-1426

Johnson NS, Yun SS, Thompson HT, Brant CO, Li W (2009) A synthesized pheromone induces upstream movement in female sea lamprey and summons them into traps. Proc Natl Acad Sci USA 106:1021-1026

Johnson NS, Thompson HT, Holbrook CM, Tix JA (2014) Blocking and guiding adult sea lamprey with vertical fields of pulsed direct current. Fish Res 150:38-48

Johnson NS, Miehls SM, O’Connor LM, Bravener G, Barber J, Thompson H, Tix JA, Bruning T (2017) A portable trap 
with electric lead catches up to $75 \%$ of an invasive fish species. Sci Rep. https://doi.org/10.1038/srep28430

Jones ML, Bergstedt RA, Twohey MB, Fodale MF, Cuddy DW, Slade JW (2003) Compensatory mechanisms in Great Lakes sea lamprey populations: implications for alternative control strategies. J Great Lakes Res 29(Suppl. 1):113-129

Jones ML, Irwin BJ, Anderson-Hansen GJ, Dawson H, Treble A, Liu W, Dai W, Bence J (2009) An operating model for the integrated pest management of Great Lakes sea lampreys. Open Fish Sci J. https://doi.org/10.2174/ 1874401X00902010059

Kelso JRM, Gardner WM (2000) Emigration, upstream movement, and habitat use by sterile and fertile sea lamprey in three Lake Superior tributaries. N Am J Fish Manag 20:144-153

Kelso JRM, Gardner WM, McDonald RB (2001) Interactions among fertile male, female, and sterile male sea lamprey during spawning in the Carp River, Lake Superior. N Am J Fish Manag 21:904-910

Kemp PS, O'Hanley JR (2010) Procedures for evaluating and prioritising the removal of fish passage barriers: a synthesis. Fish Manage Ecol 17:297-322

Kirk MA, Caudill CC, Johnson EL, Keefer ML, Clabough TS (2015) Characterization of adult Pacific Lamprey swimming behavior in relation to environmental conditions within large-dam fishways. Trans Am Fish Soc 144:998-1012

Klingler GL, Adams JV, Heinrich JW (2003) Passage of four teleost species prior to sea lamprey (Petromyzon marinus) migration in eight tributaries of Lake Superior, 1954 to 1979. J Great Lakes Res 29(Suppl. 1):403-409

Koonce JF, Eshenroder RL, Christie GC (1993) An economic injury level approach to establishing the intensity of sea lamprey control in the Great Lakes. N Am J Fish Manag 13:1-14

Lamsa AK, Rovainen CM, Kolenosky DP, Hanson LH (1980) Sea lamprey (Petromyzon marinus) control-where to from here? Report of the SLIS control theory task force. Can J Fish Aquat Sci 37:2175-2192

Larson GL, Christie GC, Johnson DA, Koonce JF, Mullett KM, Sullivan WP (2003) The history of sea lamprey control in Lake Ontario and updated estimates of suppression targets. J Great Lakes Res 29(Suppl. 1):637-654

Lasne E, Sabatié M-R, Jeannot N, Cucherousset J (2014) The effects of dam removal on river colonization by sea lamprey Petromyzon marinus. River Res Appl 31:904-911

Lavis DS, Hallett A, Koon EM, McAuley T (2003) History of and advances in barriers as an alternative method to suppress sea lamprey in the Great Lakes. J Great Lakes Res 29(Suppl. 1):362-372

Lawrie AH (1970) The sea lamprey in the Great Lakes. Trans Am Fish Soc 99:766-775

Lenson WJ, Lawrie AH (1959) The engineering aspects of sea lamprey barrier design and operation. Fish Res Bd Can, Progr Rep Biol Sta Tech Unit, No. 1, p 14

Leutheusser HJ, Birk WM (1991) Drownproofing of low overflow structures. J Hydraul Eng 117:205-213

Li W, Twohey M, Jones M, Wagner CM (2007) Research to guide use of pheromones to control sea lamprey. J Great Lakes Res 33(Special Issue 2):70-86
Lopez-Egea M (2015) Experimental and numerical modelling of submerged hydraulic jumps at low-head dams. Dissertation, University of Ottawa

MacKay H, MacGillivray E (1949) Recent investigations on the sea lamprey, Petromyzon marinus, in Ontario. Trans Am Fish Soc 77:148-159

Manion PJ, Smith BR (1978) Biology of larval and metamorphosing sea lamprey, Petromyzon marinus, of the 1960 year class in the Big Garlic River, Michigan, Part II, 1966-72. Great Lakes Fishery Commission Technical Report 30, p 42

Manzon LA, Youson JH, Holzer G, Staiano L, Laudet V, Manzon RG (2011) Thyroid hormone and retinoid X receptor function and expression during sea lamprey (Petromyzon marinus) metamorphosis. Gen Comp Endocrinol 204:211-222

Mazurek KA, Hallett A, Aktar A, Thomson J, Amos M, Katapodis C (2008) Phase I development of an improved sea lamprey barrier. Completion report to the Great Lakes Fishery Commission, Ann Arbor, p 119

McAuley TC (1996) Development of an instream velocity barrier to stop sea lamprey, (Petromyzon marinus) migrations in Great Lakes Streams. Dissertation, University of Manitoba

McCann EM, Johnson NS, Hrodey PJ, Pangle KL (2018) Characterization of sea lamprey stream entry using dual frequency identification sonar. Trans Am Fish Soc 147:514-524

McDonald DG, Desrochers D (2012) Using an eel ladder-trap to trap sea lampreys: proof of concept. Project completion report, Great Lakes Fishery Commission, Ann Arbor

McDonald DG, Stamplecoskie K (2010) Improving the effectiveness of portable sea lamprey traps. Project completion report, Great Lakes Fishery Commission, Ann Arbor

McLain AL, Smith BR, Moore HH (1965) Experimental control of sea lampreys with electricity on the south shore of Lake Superior, 1953-1960. Great Lakes Fishery Commission Technical Report, Ann Arbor 10, p 48

McLaughlin RL, Hallett A, Pratt TC, O’Connor LM, McDonald DG (2007) Research to guide use of barriers, traps, and fishways to control sea lamprey. J Great Lakes Res 33(Special Issue):7-19

McLaughlin RL, Smyth ERB, Castro-Santos T, Jones ML, Koops MA, Pratt TC, Vélez-Espino L (2013) Unintended consequences and trade-offs of fish passage. Fish Fish 14:580-604

McLean AR, McLaughlin RL (2018) Consistent individual differences in sea lamprey (Petromyzon marinus) behaviour: implications for control via trapping. J Great Lakes Res 44:482-490

McLean AR, Barber J, Bravener G, Rous AM, McLaughlin RL (2015) Understanding low success trapping invasive sea lampreys: an entry-level analysis. Can J Fish Aquat Sci 72:1876-1885

Mickle M, Miehls S, Johnson N, Higgs D (2018) Hearing capabilities and behavioural response of sea lamprey (Petromyzon marinus) to low frequency sounds. Can J Fish Aquat Sci 76:1541-1548

Miehls SM, Siefkes MJ (2015) Using a fishwheel to capture sea lampreys. Project completion report, Great Lakes Fishery Commission, Ann Arbor, p 19 
Miehls SM, Johnson NS, Haro A (2017a) Electrical guidance efficiency of downstream-migrating juvenile sea lampreys decreases with increasing water velocity. Trans Am Fish Soc 146:299-307

Miehls SM, Johnson NS, Hrodey PJ (2017b) Test of a nonphysical barrier consisting of light, sound, and bubble screen to block upstream movement of sea lamprey in an experimental raceway. N Am J Fish Manag 37:660-666

Miehls SM, Holbrook CM, Marsden JE (2019) Behavioral shift during downstream migration: seasonal change in diel activity of newly metamorphosed juvenile sea lamprey. PLoS ONE 14(2):e0211687

Moody AT, Neeson TM, Wangen S, Dischler J, Diebel MW, Milt A, Herbert M, Khoury M, Yacobson E, Doran PJ, Ferris MC, O'Hanley JR, McIntyre P (2017) Pet project or best project? Online decision support tools for prioritizing barrier removals in the Great Lakes and beyond. Fisheries 42:57-65

Moore HH, Dahl FH, Lamsa AK (1974) Movement and recapture of parasitic-phase sea lampreys (Petromyzon marinus) marked in the St. Marys River and Lakes Huron and Michigan, 1963-67. Technical report 27, Lakes Fishery Commission, Ann Arbor, p 19

Moser ML, Jackson AD, Lucas MC, Mueller RP (2015) Behavior and potential threats to survival of migrating lamprey ammocoetes and macrophthalmia. Rev Fish Biol Fish 25:103-116

Mullett KM, Heinrich JW, Adams JV, Young RJ, Henson MP, McDonald RB, Fodale MF (2003) Estimating Lake-wide abundance of spawning-phase sea lampreys (Petromyzon marinus) in the Great Lakes: extrapolating from sampled streams using regression models. J Great Lakes Res 29(Supplement 1):240-252

Northcote TG (1984) Mechanism of fish migration in rivers. NATO Conf Ser 14:317-355

O'Connor LM, Pratt TC, Hallett A, Katapodis C, Bergstedt RA, Hayes DB, McLaughlin RL (2003) A performance evaluation of fishways at sea lamprey barriers and controlled modifications to improve fishway performance. Completion report, Great Lakes Fishery Commission, Ann Arbor

Pereira E, Quintella BR, Mateus CS, Alexandre CM, Belo AF, Telhado A, Quadrado MF, Almeida PR (2017) Performance of a vertical-slot fish pass for the sea lamprey Petromyzon marinus L. and habitat recolonization. River Res Appl 33:16-26

Pratt TC, O'Connor LM, Hallett AG, McLaughlin RL, Hayes DB (2006) Evaluation of modification to improve fishway performance. Completion report, Great Lakes Fishery Commission, Ann Arbor

Pratt TC, O'Connor LM, Hallett AG, McLaughlin RL, Katopodis C, Hayes DB, Bergstedt RA (2009) Balancing aquatic habitat fragmentation and control of invasive species: enhancing selective fish passage at sea lamprey control barriers. Trans Am Fish Soc 138:652-665

Purvis HA, McDonald RB (1987) Summary of evaluation methods and population studies of spawning phase sea lamprey-Section C. In: Workshop to evaluate sea lamprey populations "WESLP." Great Lakes Fishery Commission Special Publication Series 87-2, Great Lakes Fishery Commission, Ann Arbor, pp 145-259
Purvis HA, Chudy CL, King EL, Dawson VK (1985) Response of spawning-phase sea lamprey (Petromyzon marinus) to a lighted trap. Great Lakes Fishery Commission Technical Report Series, No 42:15-25

Pycha RL, King GR (1975) Changes in the lake trout population of southern Lake Superior in relation to the fishery, the sea lamprey, and stocking, 1950-70. Great Lakes Fishery Commission Technical Report Series, No 28, p 34

Reinhardt UG, Hrodey PJ (2019) Trap happiness and catch bias in sea lamprey traps. Fishes 4:34

Reinhardt UG, Eidietis L, Friedl SE, Moser ML (2008) Pacific lamprey climbing behavior. Can J Zool 86:1264-1272

Reinhardt UG, Binder TR, McDonald DG (2009) Ability of adult sea lamprey to climb inclined surfaces. Am Fish Soc Symp 72:125-138

Reinhardt UG, Hrodey PJ, Miehls SM (2016) Refinement of a new trapping tool for migrating adult sea lamprey. Completion report 2013_REI_54039. Great Lakes Fishery Commission, Ann Arbor

Rous AM, McLean AR, Barber J, Bravener G, Castro-Santos T, Holbrook CM, Imre I, Pratt TC, McLaughlin RL (2017) Spatial mismatch between sea lamprey behaviour and trap location explains low success at trapping for control. Can J Fish Aquat Sci 74:2085-2097

Sard NM, Smith S, Homola, J, Kanefsky J, Bravener G, Adams J, Holbrook C, Hrodey P, Tallon K, Scribner KT (in press) Rapture (RAD capture) panel facilitates analyses characterizing sea lamprey reproductive ecology and movement dynamics. Ecol Evol

Sawyer AJ (1980) Prospects for integrated pest management of the sea lamprey (Petromyzon marinus). Can J Fish Aquat Sci 37:2081-2092

Schuldt RJ, Heinrich JW (1982) Portable trap for collecting adult sea lamprey. Prog Fish Cult 44:220-221

Scott DP (1959) Big Creek direct-current guider barrier for sea lamprey control. Progress report no. 1, Biological Station and Technological Unit, Fish Res Board Can, pp 18-21

Shetter DS (1945) Results of the 1945 operations at the Ocqueoc River sea lamprey weir. Michigan Department of Fisheries Research, Institute of Fisheries Research No. 1015, Lansing

Shetter DS (1949) A brief history of the sea lamprey problem in Michigan waters. Trans Am Fish Soc 77:160-176

Siefkes MJ, Steeves TB, Sullivan WP, Twohey MB, Li W (2013) Sea lamprey control: past, present, and future. In: Taylor WW, Lynch AJ, Leonard NJ (eds) Great Lakes fisheries policy and management: a binational perspective, 2nd edn. Michigan State University Press, East Lansing, pp 651-704

Smith BR, Tibbles JJ (1980) Sea lamprey (Petromyzon marinus) in Lakes Huron, Michigan and Superior: history of invasion and control, 1936-78. Can J Fish Aquat Sci 37:1780-1801

Smyth E (2011) A quantitative evaluation of fish passage options for the dam on the Black Sturgeon River. Dissertation, University of Guelph

Solomon DJ, Beach MH (2004) Fish pass design for eel and elver (Anguilla anguilla). R\&D technical report W2-070/ TR1, Environment Agency, Bristol 
Sotola VA, Miehls SM, Simard LG, Marsden JE (2018) Spatial distribution of downstream migrating juvenile sea lamprey. J Great Lakes Res 44:491-496

Stamplecoskie KM, Binder TR, Lower N, Cottenie K, McLaughlin RL, McDonald DG (2012) Response of migratory sea lampreys to artificial lighting in portable traps. N Am J Fish Manag 32:563-572

Stauffer TM (1964) An experimental sea lamprey barrier. Prog. Fish Cult. 26:80-83

Sullivan P, Adair R (2012) Sea lamprey control in the Great Lakes 2011. Annual report to the Great Lakes Fishery Commission, Great Lakes Fishery Commission, Ann Arbor

Sullivan P, Mullett K (2018) Sea lamprey control in the Great Lakes 2017. Annual report to the Great Lakes Fishery Commission, Great Lakes Fishery Commission, Ann Arbor

Sullivan WP, Christie CG, Cornelius FC, Fodale MF, Johnson DA, Koonce JF, Larson GL, McDonald RB, Mullett KM, Murray CK, Ryan PA (2003) The sea lamprey in Lake Erie: a case history. J Great Lakes Res 29(Suppl. 1):615-636

Teeter J (1980) Pheromone communication in sea lampreys (Petromyzon marinus): implications for population management. Can J Fish Aquat Sci 37:2123-2132

Van Oosten J (1947) Mortality of smelt, Osmerus mordax (Mitchill), in Lakes Huron and Michigan during the fall and winter of 1942-43. Trans Amer Fish Soc 74:310-337

Velez-Espino LA, McLaughlin RL, Jones ML, Pratt TC (2011) Demographic analysis of trade-offs with deliberate fragmentation of streams: control of invasive species versus protection of native species. Biol Conserv 144:1068-1080

Volkhardt GC, Johnson SL, Miller BA, Nickelson TE, Seiler DE (2007) Rotary screw traps and inclined plane screen traps.
In: Johnson DH, Shrier BM, O'Neal JS, Knutzen JA, Augerot X, O'Neil TA, Pearsons TN (eds) Salmonid field protocols handbook: techniques for assessing status and trends in salmon and trout populations. American Fisheries Society, Bethesda, pp 235-266

Wilkie MP, Hubert TD, Boogaard MA, Birceanu O (2019) Control of invasive sea lampreys using the piscicides TFM and niclosamide: toxicology, successes \& future prospects. Aquat Tox 211:235-252

Young R, Cuddy D, McDonald R (1996) The effect of velocity barrier construction in the McIntyre River on the fish and lamprey community. Completion report, Great Lakes Fishery Commission, Ann Arbor

Youngs WD (1979) Evaluation of barrier dams to adult sea lamprey migration. Completion report, Great Lakes Fishery Commission, Ann Arbor

Youson JH (1980) Morphology and physiology of lamprey metamorphosis. Can J Fish Aquat Sci 37:1687-1710

Youson JH (2003) The biology of metamorphosis in sea lampreys: endocrine, environmental, and physiological cues and events, and their potential application to lamprey control. J Great Lakes Res 29(Suppl. 1):26-49

Zielinski DP, McLaughlin RL, Castro-Santos T, Paudel B, Hrodey PJ, Muir AM (2019) Alternative sea lamprey barrier technologies: history as a control tool. Rev Fish Sci Aquac 27:438-457

Publisher's Note Springer Nature remains neutral with regard to jurisdictional claims in published maps and institutional affiliations. 